\title{
Sex differences in predictors of ischemic stroke: current perspectives
}

\author{
This article was published in the following Dove Press journal: \\ Vascular Health and Risk Management \\ 27 July 2015 \\ Number of times this article has been viewed
}

\author{
Alyana A Samai ${ }^{1,2}$ \\ Sheryl Martin-Schild' \\ 'Department of Neurology, Stroke \\ Program, Tulane University School \\ of Medicine, ${ }^{2}$ Department of \\ Epidemiology, Tulane School of Public \\ Health and Tropical Medicine, New \\ Orleans, LA, USA
}

\begin{abstract}
Globally, stroke is a significant public health concern affecting more than 33 million individuals. Of growing importance are the differences between males and females in the predictors and overall risk of stroke. Given that women have a higher lifetime risk for stoke and account for more than half of all stroke deaths, sex-specific stroke risk factors merit investigation and may help target public health interventions. This review aims to discuss the current body of knowledge regarding sex-specific predictors of ischemic stroke including both modifiable and non-modifiable risk factors, as well as specific pathologies known to increase stroke risk.
\end{abstract}

Keywords: thrombosis, risk factors, sex, cerebral stroke

\section{Introduction}

Stroke affects 33 million individuals worldwide each year. ${ }^{1}$ As of 2012, stroke was the third leading cause of death and the third leading cause of years of life lost due to premature mortality worldwide. ${ }^{2}$ In the US, stroke is the fourth leading cause of death, accounting for 1 in 20 deaths, and is the leading cause of serious long-term disability. According to the Centers for Disease Control and Prevention, stroke accounted for $33 \%$ of potentially preventable deaths in the US between 2008 and $2010 .{ }^{3}$ Nearly $87 \%$ of all strokes are ischemic. ${ }^{1}$

Stroke in women is a growing public health concern. Stroke is the fourth leading cause of death in women ages 20-59 worldwide; by current estimates, women account for approximate $60 \%$ of all stroke deaths. ${ }^{1,4}$ In the $>60$ age group, stroke is the second leading cause of death among women. Recent research has also suggested that, among first-ever stroke patients, women are more frequently older, are more likely to have hypertension, atrial fibrillation (Afib), and cardioembolic infarction, and experience reduced mortality and length of hospitalization. ${ }^{5}$

Among elderly stroke patients, $43 \%$ experienced moderate-to-severe neurological deficits post-stroke. ${ }^{6}$ However, of these, women more frequently need assistance with activities of daily living and walking, and more often live in nursing homes after their stroke. Within the first 6 months after their stroke, women more often have disabilities of greater severity and extent than their male counterparts. In a subanalysis of the Framingham Heart Study, it was found that women were more disabled and 3.5 times as likely to be institutionalized at 3-6 months post-stroke compared with men. ${ }^{7}$ Furthermore, the women in this cohort more frequently classified as a first-stroke event.

Compared with males, females have a higher lifetime risk for stroke, are more likely to experience recurrent stroke, and are more likely to have more severe strokes. ${ }^{1}$ 
Patients with recurrent stroke are recognized to have as much as a $38 \%$ greater cost per patient-year after discharge from acute stroke hospitalization when compared with first-ever stroke patients. ${ }^{1}$ As such, understanding the predictors of stroke unique to females is of significant import.

This article will explore differences in the risk among males and females posed by various predictors of stroke including non-modifiable risk factors, modifiable risk factors, and specific disease pathologies.

\section{Non-modifiable risk factors Sex differences in age}

According to 2010 US Census Data, the 65+ age group accounts for $13 \%$ of the total US population; of these, $56.9 \%$ are female. ${ }^{8}$ Nearly $75 \%$ of all strokes occur in individuals over 65 years old. ${ }^{9}$ As of 2014, women worldwide have surpassed their male counterparts with respect to at-birth life expectancy by nearly 10 years on average. ${ }^{6}$ In the US, the estimated at-birth life expectancy is 81.94 years for females compared with 79.56 years for males; after 65 years, life expectancy is 20.50 years for females and 17.90 years for males. ${ }^{10}$ On average, women are about 4 years older than men at the time of their first stroke. ${ }^{1}$

Overall, the incidence rate of stroke is 1.25 times higher in males compared with females and increases steadily with age for both males and females. ${ }^{11}$ Given that a greater proportion of the population is female and females are likely to live longer, it logically follows that females account for nearly $60 \%$ of post-stroke mortality. ${ }^{12}$

Recent research has also demonstrated that women are older at the time of their first stroke. Appelros et al found that, in 98 studies spanning 19 countries and 5 continents, the mean age of first-ever stroke is 72.9 years in women compared with 68.6 years in men. ${ }^{13}$ Research has also shown that, due to longer lifespan, women have more strokes during their lifetime. ${ }^{12}$

\section{Sex differences in race}

Differences are recognized in the prevalence of stroke between races. According to 2013 data from the Behavioral Risk Factor Surveillance System, American Indians/Alaska Natives exhibited the highest prevalence of history of stroke $(4.6 \%)$, tied with other races/multiracial individuals. ${ }^{1}$ Non-Hispanic blacks had the next highest prevalence $(4.0 \%)$, followed by non-Hispanic whites (2.5\%), Hispanics (2.3\%), and Asian/ Pacific Islanders (1.3\%). Furthermore, between 2006 and 2010 , individuals of black race had a higher prevalence of stroke compared with other races. Although the current evidence suggests a decline in the overall incidence of stroke among whites when comparing 2005 with earlier years, this decline has not been observed among blacks.

With respect to short-term outcomes following ischemic stroke, race and sex do not appear to significantly modify the relationship. ${ }^{14}$ However, racial differences do exist in stroke mortality when stratified by sex. Compared with white men, black men experience a 1.4 times increased risk for stroke-related mortality. ${ }^{15}$ Interestingly, black women experienced a twofold increased risk (risk ratio $=2.0$ ) when compared with white women. Some evidence also suggests that socioeconomic status may account for some of the risk attributed to stroke among black men; however, evidence for this relationship is limited. ${ }^{16}$

\section{Modifiable risk factors Sex differences relating to hypertension}

Approximately $77 \%$ of individuals who have an incident stroke have blood pressure greater than $140 / 90 \mathrm{mmHg} .{ }^{17}$ The attributable risk for ischemic stroke due to hypertension is approximately $26 \% .{ }^{18}$ As of 2008 , the prevalence of hypertension was approximately $40 \%$ in adults over 25 years of age, affecting $29.2 \%$ of males and $24.8 \%$ of females worldwide. ${ }^{2}$ In the US, among adults $\geq 20$ years old, the prevalence of hypertension varies by both race and sex as follows: among non-Hispanic whites, $33.4 \%$ for men and $30.7 \%$ for women; among non-Hispanic blacks, $42.6 \%$ for men and $47.0 \%$ for women; and among Mexican Americans, 30.1\% for men and $28.8 \%$ for women. ${ }^{17}$ In the $<45$ age group, more men than women have hypertension, in the 45-64 age group, the proportion of men and women with hypertension is approximately equal, and in the $>64$ age group, far more women than men have hypertension. Physical inactivity may be influencing this fluctuation in hypertension rates as women are more likely than men to be inactive in all age ranges $(33.2 \%$ vs $29.9 \%) .{ }^{19}$

Data from the National Health and Nutrition Examination Survey between 2007 and 2010 showed that, of individuals with high blood pressure in the US, approximately $47.5 \%$ do not have it controlled. ${ }^{17}$ Furthermore, control rate among older women is lower than for older men. ${ }^{19}$ It has been demonstrated that controlling blood pressure reduces the incidence of ischemic stroke. ${ }^{20,21}$ Additionally, lower rates of recurrent stroke have been associated with lower blood pressures. ${ }^{1}$ In the US alone, the indirect and direct costs of hypertension were estimated to be more than $\$ 46$ billion, suggesting that better management of hypertension could have a significant economic impact. ${ }^{17}$ 


\section{Sex differences relating to diabetes mellitus}

Globally, in 2014, the prevalence of diabetes mellitus (DM) was 9\% among adults over 18 years of age. ${ }^{22}$ An estimated 347 million individuals have DM worldwide. ${ }^{23}$ Of the 29.1 million individuals with DM in the US, approximately 8.1 million are undiagnosed. ${ }^{24}$ More than $50 \%$ of individuals with DM will die from a cardiovascularrelated cause. ${ }^{22}$

The diabetic stroke patient is more likely to be younger, have hypertension, and have slower recovery time compared with non-diabetic patients. ${ }^{25}$ Furthermore, stroke patients with diabetes are more likely to die as a result of the stroke. In those $<55$ years of age, the risk for stroke is ten times greater in diabetics compared with non-diabetics. ${ }^{26}$ Women with DM are also at increased risk for stroke compared with their male counterparts, possibly due to the relationship between DM and atherosclerosis. In the Framingham study cohort, diabetic women had a 3.5 times higher risk for stroke compared with non-diabetic women, whereas diabetic men had a 2.1 times higher risk for stroke compared with non-diabetic men. ${ }^{27}$

\section{Sex differences relating to dyslipidemia} Total cholesterol

Regardless of sex, the relationship between total cholesterol and stroke remains unclear. Although the mechanism by which high cholesterol levels may lead to stroke is widely agreed upon, the current body of literature regarding cholesterol and ischemic stroke may be subject to bias. In many studies, both hemorrhagic and ischemic stroke were evaluated in tandem, thereby clouding the association. ${ }^{28}$ Furthermore, many studies appear to frequently include fatal stroke as an endpoint, again leading to bias. ${ }^{29}$ Overall, it appears that total cholesterol may have a cooperative effect with other factors that may contribute to the atherosclerotic process and, by extension, contribute to rates of ischemic stroke.

\section{High-density lipoprotein}

High-density lipoprotein (HDL) appears to have a direct association with ischemic stroke. Men and women have comparable HDL levels until puberty, but the level of HDL decreases significantly in men during adolescence to a normal adult level..$^{30}$ In women, there is a steady increase in HDL levels over time, possibly contributing to the later presentation of carotid disease. ${ }^{31}$ Several studies have demonstrated increased rates of ischemic stroke among men with low levels of HDL, though that relationship has not yet been established among women. ${ }^{28}$ In both men and women, every $1 \mathrm{mmol} / \mathrm{L}$ increase in HDL is associated with a $47 \%$ reduction in ischemic stroke.

\section{Low-density lipoprotein}

Evidence regarding the association between low-density lipoprotein (LDL) and ischemic stroke is limited. Overall, high LDL levels appear to correlate with thrombosis, particularly large vessel atherothrombosis..$^{32}$ In both men and women, it appears that elevated LDL confers a marginal increase in risk for ischemic stroke. ${ }^{33}$

\section{Triglycerides}

The relationship between triglycerides and ischemic stroke remains a subject of debate. Some studies have suggested that high triglycerides are not related to an increased risk for ischemic stroke. ${ }^{34}$ More recent research appears to contradict that theory. In 2008, the Copenhagen Heart Study found high triglyceride levels to be associated with increased risk for ischemic stroke in both men and women. However, in both the $<55$ and $>55$ age groups, the 10 -year risk was greater in men than in women $(2.6 \%$ and $16.7 \%$ vs $1.9 \%$ and $12.2 \%){ }^{35}$ In 2011, Varbo et al corroborated these findings with their study results that suggested a stepwise relationship between triglyceride level and ischemic stroke risk. ${ }^{36}$

\section{Sex differences relating to smoking}

In the US, more than $20 \%$ of adult males smoke compared with $\sim 15 \%$ in adult females. ${ }^{37}$ Interestingly, men tend to have higher quit rates compared with women, which further supports the modifiability of this risk factor. ${ }^{38,39}$ In both sexes, smoking is associated with an increased risk for stroke, and quitting is associated with a reduction of that risk. ${ }^{40}$ Furthermore, women who smoke appear to have a greater overall disease risk associated with smoking compared with men, especially in relation to disease processes that may also lead to ischemic stroke. ${ }^{40,41}$ A meta-analysis demonstrated a dose response with regard to risk of stroke, higher risk associated with subarachnoid hemorrhage (relative risk [RR] 2.93) than ischemic stroke (RR 1.92), and overall greater risk in women (RR 1.72) compared with men (RR 1.43). ${ }^{42}$

\section{Sex differences relating to obstructive sleep apnea}

Worldwide, the prevalence of obstructive sleep apnea (OSA) in adults is somewhere between $3 \%$ and $7 \%$ in the general 
population. ${ }^{43}$ OSA is more common in men than in women. Newman et al described the incidence of OSA over a 5-year period to be about $11.1 \%$ in men and $4.9 \%$ in women. ${ }^{44}$ However, the symptoms most commonly described by women with OSA are non-traditional, including insomnia and depression, which may mean that under-diagnosis exists among women. ${ }^{45}$ Obesity, upper airway anatomy, sleep patterns and arousal, sex hormones - specifically changes associated with menopause, and respiratory control, are all associated with OSA and are modified by sex.

In both men and women, OSA is significantly associated with an increased risk for ischemic stroke and mortality. ${ }^{46-48}$ Whether or not a difference exists between males and females in ischemic stroke risk is not well described in the literature and is worth future investigation.

\section{Sex differences relating to substance abuse}

Among women, the lifetime estimate is between 5\% and 8\% for alcohol-related disorders and between 5\% and 6\% for other drug-related disorders. ${ }^{49}$ The alcohol and illicit drug use is more prevalent among men, but recent trends indicate that the prevalence of heavy alcohol use among women is approaching that of men. Alcohol has an unique effect that is observed across sexes: in light-to-moderate amounts, it appears to have either no effect or a protective effect relating to ischemic stroke risk; however, in excessive amounts, it has inconsistently been associated with increased risk for ischemic and hemorrhagic stroke. ${ }^{50-52}$ Almost every commonly used drug type is associated with ischemic stroke including cocaine, amphetamine, opioids, cannabis, lysergic acid diethylamide, and anabolic steroids. ${ }^{53}$ The illicit drug use is associated with about $14 \%$ of all ischemic and hemorrhagic strokes, stroke in young adults ( $<45$ years old) and male sex. ${ }^{49,54}$ In a recent meta-analysis, the J-shaped relationship between ischemic stroke, hemorrhagic stroke, and even stroke mortality was confirmed. ${ }^{55}$

\section{Specific pathologies predicting ischemic stroke Sex differences relating to large artery disease}

Annually, severe carotid stenosis $(>75 \%)$ is associated with a $3.3 \%$ rate of stroke and a $7.2 \%$ rate of transient ischemic attack. ${ }^{56}$ Among adults age 33-45 years, the prevalence of carotid calcium is higher among males, irrespective of race. ${ }^{1}$ This difference is consistent when examined across races in adults age $45-84$ years. Male sex is associated with higher likelihood of detecting extracranial and combined intracranial and extracranial artery stenosis among patients admitted with first-ever ischemic stroke. ${ }^{57,58}$

In women, coronary disease generally present $10-15$ years later than in men. ${ }^{31}$ This may be due to sex differences in various risk factors for carotid artery disease. The Rotterdam Elderly Study determined that hypertension, smoking, and low levels of HDL are risk factors for developing carotid disease in the elderly population..$^{59}$ Each of these factors has also been independently linked as risk factors for ischemic stroke, as discussed earlier in this review. ${ }^{60-62}$

For patients with carotid disease, revascularization through the use of stenting or endarterectomy is a current component of standard-of-care guidelines, when a patient meets the necessary criteria. ${ }^{63}$ A subgroup analysis from the Carotid Revascularization Endarterectomy versus Stenting Trial revealed no difference between men and women in the rates of the primary endpoint defined as "the composite of any stroke, myocardial infarction, or death during the periprocedural period or ipsilateral stroke within 4 years after randomization". ${ }^{64}$ However, the risk for periprocedural stroke was higher in women in the stenting group; no such difference was detected in men. The American Heart Association/American Stroke Association (AHA/ASA) Guidelines for the Prevention of Stroke in Women advise that there is insufficient evidence to manage men and women differently with regard to choice of revascularization modality for symptomatic carotid stenosis. ${ }^{65}$

\section{Sex differences in small artery disease}

The case-fatality rate of small vessel stroke (subcortical infarct $<15 \mathrm{~mm}$ in diameter occluding a single perforating artery), sometimes referred to as a silent or lacunar infarct, is low at approximately $2.5 \%$ at 1 month. ${ }^{66} \mathrm{~A}$ study conducted by Vermeer et al in an elderly population (60-90 years old) found a prevalence of radiographic small vessel stroke of $20 \%$ and an increase in the odds of small vessel stroke with age ${ }^{67}$ Furthermore, this study of persons of advanced age found a higher prevalence of small vessel stroke in women. Another study by Bejot et al that examined more than 2,000 ischemic stroke cases of all ages from 1989 to 2006 found a prevalence of $28 \%$ for small vessel stroke. The incidence of small vessel stroke increased steadily with age, but was overall higher in men than in women (18.3 vs 10.3 per 100,000 persons per year). ${ }^{66}$ Interestingly, one study has found that in patients in the over 85-year category, small vessel stroke showed a significantly higher proportion of 
women. ${ }^{68}$ Women with small vessel stroke tend to be older and more frequently have a history of obesity and hypertension as compared with men. ${ }^{69}$

Small vessel disease is regarded as a leading cause of vascular-related cognitive impairment. By current estimates, $30 \%$ of patients who experience a small vessel stroke will have some cognitive impairment, ranging from mild cognitive impairment to dementia, in the 4 years post-stroke, regardless of sex. ${ }^{70}$ No evidence of a sex modifier for vascular dementia exists, in contrast to female predominance of Alzheimer's type of dementia. ${ }^{71}$

\section{Sex differences in predictors of cardioembolic stroke}

\section{Atrial fibrillation}

Afib is a known risk factor for ischemic stroke. ${ }^{1}$ The incidence of Afib in men is significantly higher (20.6 per 100,000 persons) compared with women ( 6.6 per 100,000 persons) in the 15-44 age range. However, in the $>85$ age group, the incidence of Afib is slightly higher in women (1,203.7 per $100,000$ persons) than in men (1,077.4 per 100,000 persons $)$. The prevalence of Afib is consistently higher in men than in women across age groups and races.

In the absence of valvular heart disease, the risk of stroke increases fivefold for individuals with Afib. ${ }^{72}$ This increased risk may be due to the prothrombotic effect of endothelial dysfunction and inflammation resulting from Afib. Women appear to be at a greater risk for thromboembolism due to Afib than men when not on anticoagulation therapy (warfarin). ${ }^{73}$ In fact, the efficacy of warfarin may be comparable, if not greater, in women as compared with men. However, a consensus has not yet been achieved regarding the risk for major bleeding while using warfarin, with some research suggesting equal rates between men and women, and others suggesting a greater risk in women. ${ }^{73,74} \mathrm{~A}$ recent meta-analysis supports improved efficacy of preventing stroke or systemic embolism coupled with lower risk of major bleeding in women compared with men who are treated with novel oral anticoagulants. ${ }^{75}$

\section{Heart failure}

More than 23 million people have heart failure (HF) worldwide. ${ }^{76}$ A subanalysis from the Framingham cohort found that the overall incidence of HF to be higher in men than in women (5.64 vs 3.27 per 1,000 person-years) with proportional increases with age for both sexes. ${ }^{77}$ In women, $\mathrm{HF}$ tends to occur later and is more commonly associated with obesity, chronic kidney disease, Afib, hypertension, and preserved left ventricle (LV) ejection fraction. ${ }^{78-81}$ In men, HF is associated with different comorbidities including anemia, myocardial infarction, chronic obstructive and pulmonary disease, and peripheral arteriopathy. ${ }^{78}$ Overall, the risk of ischemic stroke is increased in the presence of reduced LV ejection fraction, irrespective of sex. However, a dose response (higher risk with moderate-to-severely reduced vs mildly reduced LV function) was detected only in men. ${ }^{82}$

\section{Sex differences in hormonal effects Sex hormones}

Research suggests that women experience a neuroprotective effect pre-menopause, likely relating to circulating ovarian hormones, particularly estrogen. Although the exact age ranges vary between studies, generally, women appear to experience a decreased risk for stroke between 40 and 75 years of age compared with men, but after 75 , women experience around $50 \%$ greater risk for stroke than men. ${ }^{83}$

Sex hormones play a significant role in reactivity of the cerebral vasculature. ${ }^{84}$ In vivo, testosterone and estrogen appear to have opposing influences on reactivity of cerebral arteries, with estrogen having a vasodilation effect that may even counteract the effect of other serum vasoconstrictors. Other research has also identified that female arteries are generally less constricted possibly as a result of effect estrogen has on nitric oxide production in the endothelium. ${ }^{85}$ Though not widely investigated in the literature, some researchers have hypothesized that, rather than estrogen lending a protective effect to women, perhaps males' elevated risk is due to adverse effects of androgens. ${ }^{31}$ The biochemical mechanisms relating to these sex hormones and the sex differences associated with them are beyond the scope of this article, but has been extensively detailed in a review by Krause et al. ${ }^{84}$

Pre-menopausal women have the strongest cerebral reactivity when evaluated using transcranial Doppler ultrasonography. ${ }^{86,87}$ When matched with premenopausal women of the same age, postmenopausal women have significantly lower reactivity. However, when treated with hormone replacement therapy, the reactivity in postmenopausal women was similar to that of premenopausal women. Despite this response, several studies have demonstrated a lack of effect of hormone replacement therapy on reducing stroke incidence and mortality. ${ }^{88-90}$ In fact, many studies have shown an increased incidence of ischemic stroke in addition to increased rates of both mortality and morbidity 
post-stroke. ${ }^{1,90}$ However, these findings contradict the protective effects seen in animal models and the biological effects seen in humans. Additionally, other studies have demonstrated a positive protective effect of hormone replacement against other coronary disease. ${ }^{91,92}$ Exogenous hormones may have different effects on stimulation of clotting factor formation than endogenous hormones. Currently, the body of research regarding hormone replacement therapy in relation to stroke has focused on primary and secondary prevention. Further research is warranted to determine the efficacy vs harm of hormone replacement as a treatment in acute ischemic stroke.

\section{Oral contraceptives use}

Premenopausal women, while inherently at decreased risk for ischemic stroke, may be at elevated risk if they use oral contraceptives (OC). The exact amount of increased risk attributed to the use of hormonal OC has been the subject of much debate. In the US, from 2006 to 2010, the Centers for Disease Control and Prevention reported that $82 \%$ of sexually ever-active women between 15 and 44 years of age used OC as a contraceptive method. ${ }^{93}$ It is thought that estrogen/ progestogen OC have a procoagulant effect by increasing the activity of various clotting factors within the coagulation cascade, including plasma fibrinogen, while decreasing the amount of anticoagulation factors. ${ }^{94}$

Several studies have indicated elevated risk for venous thrombosis, myocardial infarction, and stroke in current OC users regardless of OC subtype. ${ }^{95}$ In a meta-analysis of 16 studies by Gillum et al, current OC users were at 2.75 times increased risk for ischemic stroke. ${ }^{96}$ Interestingly, the same study revealed a lower RR for ischemic stroke in estrogen doses $<50 \mu \mathrm{g}$ (2.08) compared with estrogen doses $>50 \mu \mathrm{g}$ (4.53). Furthermore, low-dose OC have been demonstrated to pose a $93 \%$ increased risk for ischemic stroke, though absolute increased risk is low at 4.1 ischemic strokes per 100,000 women. ${ }^{1}$ However, those using lowerdose estrogen contraceptives still experienced elevated risk. Other case-control studies have corroborated these findings and have demonstrated an at least two times increased odds for ischemic stroke among OC users when compared with controls..$^{97,98}$

\section{Pregnancy}

Pregnancy is an additional risk factor for ischemic stroke in women. Although the risk for stroke secondary to pregnancy has been explored, a consensus on the etiology of that risk or the level of increased risk has not yet been achieved.
A literature review by Wiebers suggested as much as a 13-fold increase in the risk of ischemic stroke for pregnant women. ${ }^{99}$ It has also been suggested that women's risk is greatest during the postpartum period, though the exact reason for this is undetermined. Kittner et al reported that the RR for cerebral infarct during pregnancy was 0.7 , but increased to 8.7 in the postpartum period. ${ }^{100}$ Similarly, Jaigobin and Silver reported that a majority of women presented during the last trimester or postpartum. ${ }^{101}$ With the exception of subarachnoid hemorrhage, the attributable excess risk of all types of stroke during the pregnancy/postpartum period was 8.1 per $100,000 .{ }^{1}$ It has been suggested that this association may be due, at least in part, to the hormonal changes that occur during pregnancy. Clotting activity increases during pregnancy, possibly due to placental expulsion. ${ }^{102,103}$ It is hypothesized that the natural elevation of estradiol during pregnancy may cause increases in the activity levels of various plasma coagulation factors including factor VII and plasminogen activator inhibitor. ${ }^{104}$ It has also been shown that levels of factors V, VIII, IX, X, XII, fibrinogen, and von Willebrand factor (vWF) all increase during pregnancy. ${ }^{102}$ Elevated levels of these factors have been positively correlated with increased risk for stroke and may provide a linkage between pregnancy and increased stroke risk. ${ }^{105-112}$

\section{Sex differences in hypercoagulability}

Hypercoagulability, particularly with respect to elevated Factor VIII (FVIII) and vWF, has recently been described as a potential risk factor for ischemic stroke. FVIII elevation has been shown to correlate to worse baseline stroke severity and an increased frequency of neuroworsening during the acute hospitalization. ${ }^{106}$ Furthermore, combined elevation in FVIII and vWF appears to confer increased odds of poor functional outcome, inpatient complications, neuroworsening, and recurrent thrombotic events during acute hospitalization. ${ }^{107}$ Among older patients, elevated FVIII appears to be associated with an increased risk for thrombosis and stroke in women. ${ }^{113-117}$

Although FVIII has traditionally been viewed as an acute phase reactant, a recent study found that post-ischemic stroke, FVIII levels appear to remain elevated remote from index stroke in a majority of patients whose levels were elevated during the acute phase of ischemic stroke. ${ }^{118}$ The study developed prediction models for determining which patients would experience persistently elevated FVIII at the two most commonly used activity thresholds, $150 \%$ and $200 \%$. In both models, female sex was included as a predictor of persistent FVIII elevation. The correlation between elevated 
FVIII and the risk for ischemic stroke suggests that these persistently elevated levels may be a player in women's propensity for multiple strokes. Additionally, the hormonal effects mentioned above may be related to the impact of hypercoagulability in women.

\section{Conclusion}

Men and women differ in their risk with respect to various predictors of ischemic stroke including age, carotid disease, hormonal changes, cardiac arrhythmias, and hypercoagulability. Further research is warranted in each of these areas to better understand the complexities of the effect of sex on ischemic stroke risk, etiology, and progression.

\section{Disclosure}

The authors report no conflicts of interest in this work.

\section{References}

1. Mozaffarian D, Benjamin EJ, Go AS, et al. Executive summary: heart disease and stroke statistics - 2015 update: a report from the American Heart Association. Circulation. 2015;131(4):434-441.

2. World Health Organization. World Health Statistics 2014. Geneva: World Health Organization; 2014.

3. Yoon PW, Bastian B, Anderson RN, Collins JL, Jaffe HW. Potentially preventable deaths from the five leading causes of death - United States, 2008-2010. MMWR Morb Mortal Wkly Rep. 2014;63(17):369-374.

4. World Health Organization. Women and Health: Today's Evidence Tomorrow's Agenda. Geneva: World Health Organization; 2009.

5. Arboix A, Cartanyà A, Lowak M, et al. Gender differences and womanspecific trends in acute stroke: results from a hospital-based registry (1986-2009). Clin Neurol Neurosurg. 2014;127:19-24.

6. Kelly-Hayes M, Beiser A, Kase CS, Scaramucci A, D’Agostino RB, Wolf PA. The influence of gender and age on disability following ischemic stroke: the Framingham study. $J$ Stroke Cerebrovasc Dis. 2003;12(3):119-126

7. Petrea RE, Beiser AS, Seshadri S, Kelly-Hayes M, Kase CS, Wolf PA. Gender differences in stroke incidence and poststroke disability in the Framingham heart study. Stroke. 2009;40(4):1032-1037.

8. Howden LM, Meyer JA. Age and Sex Composition: 2010. 2010 Census Briefs. Washington, DC: US Department of Commerce, Economics and Statistics Administration, US Census Bureau; 2010.

9. West LA. $65+$ in the United States: 2010. Washington, DC: US Census Bureau; 2010.

10. Kochanek KD, Murphy SL, Xu J, Arias E. Mortality in the United States, 2013. NCHS Data Brief. 2014(178):1-8.

11. Murphy SJ, McCullough LD, Smith JM. Stroke in the female: role of biological sex and estrogen. ILAR J. 2004;45(2):147-159.

12. West LA, Cole S, Goodkind D, He W. 65+ in the United States: 2010. Washington, DC: US Census Bureau; 2014:23-212.

13. Appelros P, Stegmayr B, Terént A. Sex differences in stroke epidemiology a systematic review. Stroke. 2009;40(4):1082-1090.

14. Boehme AK, Siegler JE, Mullen MT, et al. Racial and gender differences in stroke severity, outcomes, and treatment in patients with acute ischemic stroke. J Stroke Cerebrovasc Dis. 2014;23(4):e255-e261.

15. Lotufo PA, Goulart AC, Bensenor IM. Race, gender and stroke subtypes mortality in São Paulo, Brazil. Arq Neuropsiquiatr. 2007;65(3B):752-757.

16. Howard G, Anderson RT, Russell G, Howard VJ, Burke GL. Race, socioeconomic status, and cause-specific mortality. Ann Epidemiol. 2000;10(4):214-223.
17. American Heart Association. High blood pressure-Statistical Fact Sheet 2014 Update. Dallas, TX: American Heart Association; 2015. Available from: http:/www.heart.org/idc/groups/heart-public/@wcm/@sop/@smd/ documents/downloadable/ucm_462020.pdf. Accessed June 23, 2015.

18. Whisnant JP. Modeling of risk factors for ischemic stroke. The Willis Lecture. Stroke. 1997;28(9):1840-1844.

19. Doumas M, Papademetriou V, Faselis C, Kokkinos P. Gender differences in hypertension: myths and reality. Curr Hypertens Rep. 2013;15(4):321-330.

20. Psaty BM, Lumley T, Furberg CD, et al. Health outcomes associated with various antihypertensive therapies used as first-line agents: a network meta-analysis. JAMA. 2003;289(19):2534-2544.

21. Chobanian AV, Bakris GL, Black HR, et al. The seventh report of the joint national committee on prevention, detection, evaluation, and treatment of high blood pressure: the JNC 7 report. JAMA. 2003;289(19):2560-2571.

22. World Health Organization. Diabetes Fact Sheet. Media Centre, editor. Geneva: World Health Organization; 2015.

23. World Health Organization. 10 Facts About Diabetes. Available from: http://www.who.int/features/factfiles/diabetes/en/. Accessed April 1, 2015.

24. Centers for Disease Control and Prevention. National Diabetes Statistics Report: Estimates of Diabetes and its Burden in the United States, 2014. Atlanta, GA: US Department of Health and Human Services; 2014.

25. Jørgensen H, Nakayama H, Raaschou HO, Olsen TS. Stroke in patients with diabetes. The Copenhagen Stroke Study. Stroke. 1994; 25(10):1977-1984.

26. Beckman JA, Creager MA, Libby P. Diabetes and atherosclerosis: epidemiology, pathophysiology, and management. JAMA. 2002;287(19):2570-2581.

27. Franconi F, Campesi I, Occhioni S, Tonolo G. Sex-gender differences in diabetes vascular complications and treatment. Endocr Metab Immune Disord Drug Targets. 2012;12(2):179-196.

28. Goldstein LB, Adams R, Alberts MJ, et al. AHA/ASA guideline. Circulation. 2006;113:e873-e923.

29. Thrift AG. Cholesterol is associated with stroke, but is not a risk factor. Stroke. 2004;35(6):1524-1525.

30. Kirkland RT, Keenan BS, Probstfield JL, et al. Decrease in plasma high-density lipoprotein cholesterol levels at puberty in boys with delayed adolescence: correlation with plasma testosterone levels. JAMA. 1987;257(4):502-507.

31. Rossouw JE. Hormones, genetic factors, and gender differences in cardiovascular disease. Cardiovasc Res. 2002;53(3):550-557.

32. Koren-Morag N, Tanne D, Graff E, Goldbourt U. Low-and high-density lipoprotein cholesterol and ischemic cerebrovascular disease: the bezafibrate infarction prevention registry. Arch Intern Med. 2002;162(9):993-999.

33. Shahar E, Chambless LE, Rosamond WD, et al. Plasma lipid profile and incident ischemic stroke the atherosclerosis risk in communities (ARIC) study. Stroke. 2003;34(3):623-631.

34. Bowman TS, Sesso HD, Ma J, et al. Cholesterol and the risk of ischemic stroke. Stroke. 2003;34(12):2930-2934.

35. Freiberg JJ, Tybjærg-Hansen A, Jensen JS, Nordestgaard BG. Nonfasting triglycerides and risk of ischemic stroke in the general population. JAMA. 2008;300(18):2142-2152.

36. Varbo A, Nordestgaard BG, Tybjærg-Hansen A, Schnohr P, Jensen GB, Benn M. Nonfasting triglycerides, cholesterol, and ischemic stroke in the general population. Ann Neurol. 2011;69(4):628-634.

37. Jamal A, Agaku IT, O’Connor E, King BA, Kenemer JB, Neff L. Current cigarette smoking among adults - United States, 2005-2013. MMWR Morb Mortal Wkly Rep. 2014;63(47):1108-1112.

38. Bjornson W, Rand C, Connett JE, et al. Gender differences in smoking cessation after 3 years in the Lung Health Study. Am J Public Health. $1995 ; 85(2): 223-230$.

39. Wetter DW, Kenford SL, Smith SS, Fiore MC, Jorenby DE, Baker TB. Gender differences in smoking cessation. J Consult Clin Psychol. 1999;67(4):555. 
40. Peters SAE, Huxley RR, Woodward M. Smoking as a risk factor for stroke in women compared with men: a systematic review and metaanalysis of 81 cohorts, including 3,980,359 individuals and 42,401 strokes. Stroke. 2013;44(10):2821-2828.

41. Mucha L, Stephenson J, Morandi N, Dirani R. Meta-analysis of disease risk associated with smoking, by gender and intensity of smoking. Gender Med. 2006;3(4):279-291.

42. Shinton R, Beevers G. Meta-analysis of relation between cigarette smoking and stroke. BMJ. 1989;298(6676):789-794.

43. Punjabi NM. The epidemiology of adult obstructive sleep apnea. Proc Am Thorac Soc. 2008;5(2):136-143.

44. Newman AB, Foster G, Givelber R, Nieto FJ, Redline S, Young T. Progression and regression of sleep-disordered breathing with changes in weight: the Sleep Heart Health Study. Arch Intern Med. 2005;165(20): 2408-2413.

45. Lin CM, Davidson TM, Ancoli-Israel S. Gender differences in obstructive sleep apnea and treatment implications. Sleep Med Rev. 2008;12(6): 481-496.

46. Yaggi HK, Concato J, Kernan WN, Lichtman JH, Brass LM, Mohsenin V. Obstructive sleep apnea as a risk factor for stroke and death. N Engl J Med. 2005;353(19):2034-2041.

47. Sahlin C, Sandberg O, Gustafson Y, et al. Obstructive sleep apnea is a risk factor for death in patients with stroke: a 10-year follow-up. Arch Intern Med. 2008;168(3):297-301.

48. Campos-Rodriguez F, Martinez-Garcia MA, Reyes-Nuñez N, Caballero-Martinez I, Catalan-Serra P, Almeida-Gonzalez CV. Role of sleep apnea and continuous positive airway pressure therapy in the incidence of stroke or coronary heart disease in women. Am J Respir Crit Care Med. 2014;189(12):1544-1550.

49. Zilberman M, Tavares H, El-Guebaly N. Gender similarities and differences: the prevalence and course of alcohol and other substance-related disorders. J Addict Dis. 2004;22(4):61-74.

50. Reynolds K, Lewis B, Nolen JDL, Kinney GL, Sathya B, He J. Alcohol consumption and risk of stroke: a meta-analysis. JAMA. 2003;289(5):579-588.

51. Jimenez M, Chiuve SE, Glynn RJ, et al. Alcohol consumption and risk of stroke in women. Stroke. 2012;43(4):939-945.

52. Djoussé L, Ellison RC, Beiser A, ScaramucciA, D’Agostino RB, Wolf PA. Alcohol consumption and risk of ischemic stroke: the Framingham Study. Stroke. 2002;33(4):907-912.

53. Fonseca AC, Ferro JM. Drug abuse and stroke. Curr Neurol Neurosci Rep. 2013;13(2):1-9.

54. Esse K, Fossati-Bellani M, Traylor A, Martin-Schild S. Epidemic of illicit drug use, mechanisms of action/addiction and stroke as a health hazard. Brain Behav. 2011;1(1):44-54.

55. Zhang C, Qin Y-Y, Chen Q, et al. Alcohol intake and risk of stroke: a dose-response meta-analysis of prospective studies. Int J Cardiol. 2014;174(3):669-677.

56. Norris JW, Zhu CZ, Bornstein NM, Chambers BR. Vascular risks of asymptomatic carotid stenosis. Stroke. 1991;22(12):1485-1490.

57. Lei C, Wu B, Liu M, Chen Y. Risk factors and clinical outcomes associated with intracranial and extracranial atherosclerotic stenosis acute ischemic stroke. J Stroke Cerebrovasc Dis. 2014; 23(5):1112-1117.

58. de Weerd M, Greving JP, de Jong AWF, Buskens E, Bots ML. Prevalence of asymptomatic carotid artery stenosis according to age and sex systematic review and metaregression analysis. Stroke. 2009;40(4):1105-1113.

59. Bots ML, Breslau PJ, Briët E, et al. Cardiovascular determinants of carotid artery disease. The Rotterdam Elderly Study. Hypertension. 1992;19(6 Pt 2):717-720.

60. Demarin V, Lisak M, Morović S, Čengić T. Low high-density lipoprotein cholesterol as the possible risk factor for stroke. Acta Clin Croat. 2010;49(4):429-439.

61. Wolf PA, D'Agostino RB, Kannel WB, Bonita R, Belanger AJ. Cigarette smoking as a risk factor for stroke: the Framingham Study. JAMA. 1988;259(7):1025-1029.
62. MacMahon S, Peto R, Collins R, et al. Blood pressure, stroke, and coronary heart disease: part 1, prolonged differences in blood pressure: prospective observational studies corrected for the regression dilution bias. Lancet. 1990;335(8692):765-774.

63. Brott TG, Halperin JL, Abbara S, et al. 2011 ASA/ACCF/AHA/AANN/ AANS/ACR/ASNR/CNS/SAIP/SCAI/SIR/SNIS/SVM/SVS guideline on the management of patients with extracranial carotid and vertebral artery disease: executive summary: a report of the American College of Cardiology Foundation/American Heart Association Task Force on Practice Guidelines, and the American Stroke Association, American Association of Neuroscience Nurses, American Association of Neurological Surgeons, American College of Radiology, American Society of Neuroradiology, Congress of Neurological Surgeons, Society of Atherosclerosis Imaging and Prevention, Society for Cardiovascular Angiography and Interventions, Society of Interventional Radiology, Society of NeuroInterventional Surgery, Society for Vascular Medicine, and Society for Vascular Surgery. Developed in collaboration with the American Academy of Neurology and Society of Cardiovascular Computed Tomography. J Am Coll Cardiol. 2011;57(8):e16-e94.

64. Howard VJ, Lutsep HL, Mackey A, et al. Influence of sex on outcomes of stenting versus endarterectomy: a subgroup analysis of the Carotid Revascularization Endarterectomy versus Stenting Trial (CREST). Lancet Neurol. 2011;10(6):530-537.

65. Bushnell C, McCullough LD, Awad IA, et al. Guidelines for the prevention of stroke in women: a statement for healthcare professionals from the American Heart Association/American Stroke Association. Stroke. 2014;45(5):1545-1588.

66. Bejot Y, Catteau A, Caillier M, et al. Trends in incidence, risk factors, and survival in symptomatic lacunar stroke in Dijon, France, from 1989 to 2006: a population-based study. Stroke. 2008;39(7):1945-1951.

67. Vermeer SE, Koudstaal PJ, Oudkerk M, Hofman A, Breteler MMB. Prevalence and risk factors of silent brain infarcts in the populationbased Rotterdam Scan Study. Stroke. 2002;33(1):21-25.

68. Arboix A, García-Eroles L, Massons J, Oliveres M, Targa C. Lacunar infarcts in patients aged 85 years and older. Acta Neurol Scand. 2000; 101(1):25-29.

69. Arboix A, Blanco-Rojas L, Oliveres M, García-Eroles L, Comes E, Massons J. Clinical characteristics of acute lacunar stroke in women: emphasis on gender differences. Acta Neurol Belg. 2014;114(2): 107-112.

70. Makin SDJ, Turpin S, Dennis MS, Wardlaw JM. Cognitive impairment after lacunar stroke: systematic review and meta-analysis of incidence, prevalence and comparison with other stroke subtypes. J Neurol Neurosurg Psychiatry. 2013;84(8):893-900.

71. Andersen K, Launer LJ, Dewey ME, et al. Gender differences in the incidence of AD and vascular dementia: The EURODEM Studies. Neurology. 1999;53(9):1992-1997.

72. Lim HS, Willoughby SR, Schultz C, et al. Effect of atrial fibrillation on atrial thrombogenesis in humans: impact of rate and rhythm. J Am Coll Cardiol. 2013;61(8):852-860.

73. Fang MC, Singer DE, Chang Y, et al. Gender differences in the risk of ischemic stroke and peripheral embolism in atrial fibrillation the AnTicoagulation and Risk factors in Atrial fibrillation (ATRIA) study. Circulation. 2005;112(12):1687-1691.

74. Humphries KH, Kerr CR, Connolly SJ, et al. New-onset atrial fibrillation sex differences in presentation, treatment, and outcome. Circulation. 2001;103(19):2365-2370.

75. Pancholy SB, Sharma PS, Pancholy DS, Patel TM, Callans DJ, Marchlinski FE. Meta-analysis of gender differences in residual stroke risk and major bleeding in patients with nonvalvular atrial fibrillation treated with oral anticoagulants. Am J Cardiol. 2014;113(3):485-490.

76. Bui AL, Horwich TB, Fonarow GC. Epidemiology and risk profile of heart failure. Nat Rev Cardiol. 2011;8(1):30-41.

77. Levy D, Kenchaiah S, Larson MG, et al. Long-term trends in the incidence of and survival with heart failure. $N$ Engl J Med. 2002;347(18): 1397-1402. 
78. Conde-Martel A, Arkuch ME, Formiga F, et al. Gender related differences in clinical profile and outcome of patients with heart failure. Results of the RICA Registry. Rev Clin Esp. Epub March 18, 2015.

79. Butler J, Kalogeropoulos AP, Georgiopoulou VV, et al. Systolic blood pressure and incident heart failure in the elderly. The Cardiovascular Health Study and the Health, Ageing and Body Composition Study. Heart. 2011;97(16):1304-1311.

80. Regitz-Zagrosek V, Brokat S, Tschope C. Role of gender in heart failure with normal left ventricular ejection fraction. Prog Cardiovasc Dis 2007;49(4):241-251.

81. Masoudi FA, Havranek EP, Smith G, et al. Gender, age, and heart failure with preserved left ventricular systolic function. J Am Coll Cardiol. 2003;41(2):217-223.

82. Hays AG, Sacco RL, Rundek T, et al. Left ventricular systolic dysfunction and the risk of ischemic stroke in a multiethnic population. Stroke. 2006;37(7):1715-1719.

83. Reeves MJ, Bushnell CD, Howard G, et al. Sex differences in stroke: epidemiology, clinical presentation, medical care, and outcomes. Lancet Neurol. 2008;7(10):915-926.

84. Krause DN, Duckles SP, Pelligrino DA. Influence of sex steroid hormones on cerebrovascular function. J Appl Physiol. 2006;101(4):1252-1261.

85. Geary GG, Krause DN, Duckles SP. Estrogen reduces myogenic tone through a nitric oxide-dependent mechanism in rat cerebral arteries. Am J Physiol Heart Circ Physiol. 1998;275(1):H292-H300.

86. Matteis M, Troisi E, Monaldo BC, Caltagirone C, Silvestrini M. Age and sex differences in cerebral hemodynamics a transcranial Doppler study. Stroke. 1998;29(5):963-967.

87. Viscoli CM, Brass LM, Kernan WN, Sarrel PM, Suissa S, Horwitz RI. A clinical trial of estrogen-replacement therapy after ischemic stroke. N Engl J Med. 2001;345(17):1243-1249.

88. Hulley S, Grady D, Bush T, et al. Randomized trial of estrogen plus progestin for secondary prevention of coronary heart disease in postmenopausal women. JAMA. 1998;280(7):605-613.

89. Wassertheil-Smoller S, Hendrix S, Limacher M, et al. Effect of estrogen plus progestin on stroke in postmenopausal women: the Women's Health Initiative: a randomized trial. JAMA. 2003;289(20):2673-2684.

90. Billeci AMR, Paciaroni M, Caso V, Agnelli G. Hormone replacement therapy and stroke. Curr Vasc Pharmacol. 2008;6(2):112-123.

91. Grady D, Rubin SM, Petitti DB, et al. Hormone therapy to prevent disease and prolong life in postmenopausal women. Ann Intern Med. 1992;117(12):1016-1037.

92. Whittington R, Faulds D. Hormone replacement therapy: II. A pharmacoeconomic appraisal of its role in the prevention of postmenopausal osteoporosis and ischaemic heart disease. Pharmacoeconomics. 1994 5(6):513-554.

93. Daniels K, Mosher WD, Jones J. Contraceptive methods women have ever used: United States, 1982-2010. Natl Health Stat Rep. 2013; 62(20):2013.

94. Bonnar J. Coagulation effects of oral contraception. Am J Obst Gynecol. 1987;157(4):1042-1048.

95. Vessey M, Mant D, Smith A, Yeates D. Oral contraceptives and venous thromboembolism: findings in a large prospective study. Br Med J (Clin Res Ed). 1986;292(6519):526.

96. Gillum LA, Mamidipudi SK, Johnston SC. Ischemic stroke risk with oral contraceptives: a meta-analysis. JAMA. 2000;284(1):72-78.

97. Ryan KA, Cole JW, Saslow K, et al. Prevention opportunities for oral contraceptive-associated ischemic stroke. Stroke. 2014;45(3):893-895.

98. Kemmeren JM, Tanis BC, van den Bosch MA, et al. Risk of Arterial Thrombosis in Relation to Oral Contraceptives (RATIO) Study: oral contraceptives and the risk of ischemic stroke. Stroke. 2002;33(5):1202-1208.

99. Wiebers DO. Ischemic cerebrovascular complications of pregnancy. Arch Neurol. 1985;4(11):1106-1113.
100. Kittner SJ, Stern BJ, Feeser BR, et al. Pregnancy and the risk of stroke. N Engl J Med. 1996;335(11):768-774.

101. Jaigobin C, Silver FL. Stroke and pregnancy. Stroke. 2000;31(12): 2948-2951.

102. Bremme KA. Haemostatic changes in pregnancy. Best Pract Res Clin Haematol. 2003;16(2):153-168.

103. Gilabert J, Aznar J, Parrilla JJ, Reganon E, Vila V, Estelles A. Alterations in the coagulation and fibrinolysis system in pregnancy, labour and puerperium, with special reference to a possible transitory state of intravascular coagulation during labour. Thromb Haemost. 1978;40(2):387-396

104. Sattar N, Greer IA, RumleyA, et al. A longitudinal study of the relationships between haemostatic, lipid, and oestradiol changes during normal human pregnancy. Thromb Haemost. 1999;81(1):71-75.

105. Zakai NA, Lange L, Longstreth WT, et al. Association of coagulationrelated and inflammation-related genes and factor VIIc levels with stroke: the Cardiovascular Health Study. J Thromb Haemost. 2011; 9(2):267-274.

106. Chang TR, Albright KC, Boehme AK, et al. Factor VIII in the setting of acute ischemic stroke among patients with suspected hypercoagulable state. Clin Appl Thromb Hemost. 2014; 20(2):124-128.

107. Samai A, Monlezun D, Shaban A, et al. Von Willebrand factor drives the association between elevated factor VIII and poor outcomes in patients with ischemic stroke. Stroke. 2014;45(9):2789-2791.

108. Biswas A, Ranjan R, Meena A, et al. Prothrombotic factors and the risk of acute onset non-cardioembolic stroke in young Asian Indians. Thromb Res. 2009;124(4):397-402.

109. Heikal NM, Murphy KK, Crist RA, Wilson AR, Rodgers GM, Smock KJ. Elevated Factor IX activity is associated with an increased odds ratio for both arterial and venous thrombotic events. Am J Clin Pathol. 2013;140(5):680-685.

110. Biasiutti FD, Berger D, Mattle HP, Lämmle B, Wuillemin WA. Hemostatic risk factors in ischemic stroke. Thromb Haemost. 2003;90(6):1094-1099.

111. Suri MFK, Yamagishi K, Aleksic N, Hannan PJ, Folsom AR. Novel hemostatic factor levels and risk of ischemic stroke: the Atherosclerosis Risk in Communities (ARIC) Study. Cerebrovasc Dis. 2010;29(5): 497-502.

112. Mishra MN, Kalra R, Rohatgi S. Clinical profile, common thrombophilia markers and risk factors in 85 young Indian patients with arterial thrombosis. Sao Paulo Med J. 2013;131(6):384-388.

113. Catto AJ, Carter AM, Barrett JH, Bamford J, Rice PJ, Grant PJ. von Willebrand factor and factor VIII: $\mathrm{C}$ in acute cerebrovascular disease. Relationship to stroke subtype and mortality. Thromb Haemost 1997;77(6):1104-1108.

114. Bank I, Libourel EJ, Middeldorp S, et al. Elevated levels of FVIII: C within families are associated with an increased risk for venous and arterial thrombosis. J Thromb Haemost. 2005;3(1):79-84.

115. Jeremic M, Weisert O, Gedde-Dahl TW. Factor VIII (AHG) levels in 1016 regular blood donors: the effects of age, sex, and $\mathrm{ABO}$ blood groups. Scand J Clin Lab Invest. 1976;36(5):461-466.

116. Conlan MG, Folsom AR, Finch A, et al. Associations of factor VIII and von Willebrand factor with age, race, sex, and risk factors for atherosclerosis. The Atherosclerosis Risk in Communities (ARIC) Study. Thromb Haemost. 1993;70(3):380-385.

117. Siegler JE, Samai A, Albright KC, Boehme AK, Martin-Schild S. Factoring in Factor VIII with acute ischemic stroke. Clin Appl Thromb Hemost. Epub February 10, 2015.

118. Samai AA, Boehme AK, Shaban A, et al. Abstract T P190: a model for predicting persistent elevation of factor VIII among patients with Acute Ischemic Stroke (AIS). Stroke. 2015;46(Suppl 1):ATP190. 


\section{Publish your work in this journal}

Vascular Health and Risk Management is an international, peerreviewed journal of therapeutics and risk management, focusing on concise rapid reporting of clinical studies on the processes involved in the maintenance of vascular health; the monitoring, prevention and treatment of vascular disease and its sequelae; and the involvement of

metabolic disorders, particularly diabetes. This journal is indexed on PubMed Central and MedLine. The manuscript management system is completely online and includes a very quick and fair peer-review system, which is all easy to use. Visit http://www.dovepress.com/ testimonials.php to read real quotes from published authors.

Submit your manuscript here: http://www.dovepress.com/vascular-health-and-risk-management-journal 